\title{
Optimization of Carbon Electrodes Derived from Epoxy-based Photoresist
}

\author{
Andrea Mardegan, ${ }^{\mathrm{a}, \mathrm{b}, *, \mathrm{z}}$ Rahul Kamath, ${ }^{\mathrm{c}}$ Swati Sharma, ${ }^{\mathrm{d}}$ Paolo Scopece, ${ }^{\mathrm{b}}$ Paolo Ugo, ${ }^{\mathrm{a}}$ \\ and Marc Madou ${ }^{\mathrm{c}, \mathrm{d}, \mathrm{e}}$ \\ ${ }^{a}$ Department of Molecular Sciences and Nanosystems, University Ca' Foscari of Venice, S. Marta, 2137 Venice, Italy \\ ${ }^{b}$ CIVEN (Coordinamento Interuniversitario Veneto per le Nanotecnologie), 30175 Venice-Marghera, Italy \\ ${ }^{c}$ Department of Biomedical Engineering, University of California, Irvine, California 92697, USA \\ ${ }^{d}$ Materials and Manufacturing Technology, University of California, Irvine, California 92697, USA \\ ${ }^{e}$ Department of Mechanical and Aerospace Engineering, University of California, Irvine, California 92697, USA
}

\begin{abstract}
In this contribution we report on results from an optimization study of SU-8 photoresist derived carbon electrodes. SU-8 derived carbon tends to be glassy in nature, however, based on the exact pyrolysis strategy and other fabrication parameters employed one can obtain a range of electrical, electrochemical and thermal properties related to the variation of the graphitic content of the thus obtained carbon. Hence, in order to obtain electrodes that emulate or improve upon the performance of commercially available glassy carbon (GC) electrodes, the right choice of pyrolysis conditions, and fabrication parameters such as the polymer patterning method, the nature of the substrate, polymer precursor film thickness and dimensions of the electrodes are all important. Carbon electrodes made employing a variety of pyrolysis times and pyrolysis end temperatures, film thicknesses and substrates are investigated by cyclic voltammetry of a redox probe $\left(\left[\mathrm{Fe}(\mathrm{CN})_{6}\right]^{4-}\right)$, resistance measurements and spectroscopic analysis (Raman and XRD). SU-8 derived carbon electrodes displayed a wide potential stability window even in acidic media comparable to that of commercially available GC electrodes. Finally, these electrodes were applied to the simultaneous detection of traces of $\mathrm{Cd}(\mathrm{II})$ and $\mathrm{Pb}(\mathrm{II})$ through anodic stripping voltammetry and detection limits as low as 0.7 and $0.8 \mu \mathrm{gL}^{-1}$ were achieved.

(C) 2013 The Electrochemical Society. [DOI: 10.1149/2.107308jes] All rights reserved.
\end{abstract}

Manuscript submitted April 8, 2013; revised manuscript received May 21, 2013. Published June 1, 2013.

Carbon is available in nature in a variety of allotropes that exhibit a wide range of mechanical, chemical, electrical and electrochemical properties based on the underlying microstructure. ${ }^{1}$ Among the various carbon allotropes, graphite and glassy carbon (GC) are widely investigated for electrochemical applications. ${ }^{2}$ Polymer derived carbons are mainly glassy in nature, i.e., their microstructure is a combination of graphitic and amorphous zones. The graphitic content of glassy carbon can be altered by tuning pyrolysis conditions and other fabrication parameters. GC exhibits a wide potential stability window and low background currents. ${ }^{1}$ It features multiple electrochemically active sites due to the random orientation of the graphitic crystallites on its surface. ${ }^{3,4}$ Carbon's chemical inertness, stability in acidic and basic media, low cost and ease of fabrication render it an attractive material for deposition of metal thin films such as mercury, ${ }^{5}$ gold $^{6}$ and more recently bismuth and antimony, ${ }^{7,8}$ metal nanoparticles ${ }^{9,10}$ and polymers ${ }^{11,12}$ employed for electroanalysis.

Recently a lot of carbon research has focused on carbon nanotubes (CNTs), ${ }^{13}$ carbon micro and nanoelectromechanical systems (C-MEMS and C-NEMS), ${ }^{14,15}$ carbon fibers, ${ }^{16}$ carbon nanospheres, ${ }^{17}$ carbon whiskers, ${ }^{18}$ and graphene. ${ }^{19,20}$ These advanced carbon materials have already found potential applications in the field of biomedical engineering, sensor technology, electronics and electrochemical devices and miniature power sources. ${ }^{21-24}$

In a typical C-MEMS process ${ }^{14,15}$ carbon electrodes are conveniently fabricated employing simple and inexpensive batch fabrication methodologies i.e., UV photolithography followed by pyrolysis. Pyrolysis in C-MEMS is often carried out in a flow of $\mathrm{N}_{2}$ gas with a standard temperature ramp-up of about $10^{\circ} \mathrm{C} / \mathrm{min}$ and a one hour dwell time at the maximum temperature of $900^{\circ} \mathrm{C}$, followed by the natural cooling down of the furnace. The pyrolysis conditions we found sensitively impact the microstructure of the C-MEMS electrodes, and as consequence they also influence the chemical and electrochemical behavior necessitating an optimization of the entire C-MEMS process. Lithographically patterned C-MEMS electrodes pyrolyzed under the standard conditions (as described above) usually result in GC with a low graphitic content. ${ }^{25}$

The C-MEMS electrodes we fabricated were first photopatterned in SU-8, a negative tone epoxy based photoresist, and then pyrolyzed. The pyrolysis in this study was performed at three final pyrolysis

*Electrochemical Society Student Member.

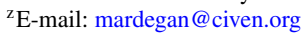

temperatures, 800,900 , and $1000^{\circ} \mathrm{C}$ with variable dwell times $(1,4$ and 8 hours) at 800 and $900^{\circ} \mathrm{C}$. Besides carrying out electrochemistry on the thus obtained electrodes we characterized them with resistivity measurements, Raman spectroscopy and X ray diffraction (XRD).

In this contribution we report on the optimization of the fabrication of C-MEMS electrodes that may be employed for biological applications, ${ }^{26,27}$ chemical sensing ${ }^{28}$ and microbatteries. ${ }^{29}$ Moreover for the first time, we apply pyrolyzed photoresist electrodes for the analysis of heavy metals ions.

\section{Experimental}

Materials and methods. - Standard solutions of $\mathrm{Bi}(\mathrm{III}), \mathrm{Pb}(\mathrm{II})$ and $\mathrm{Cd}(\mathrm{II})\left(1000 \mathrm{mg} \mathrm{L}^{-1}\right)$ were purchased from Merck and diluted as required with $0.01 \mathrm{M} \mathrm{HCl}$. All other reagents, such as ferrocyanide and $\mathrm{KCl}$, were analytical grade. SU-8 was procured from MicroChem Inc. MA, USA. Silicon wafers were obtained from Noel Technologies, CA, USA.

Electrode preparation.- A negative tone epoxy based photoresist, SU-8 was photopatterned employing standard UV photolithography. The wafers were dehydrated for 30 minutes at $120^{\circ} \mathrm{C}$ right before the application of the photoresist. The photoresist was applied manually on the wafers and was spin-coated according to manufacturer's specifications ${ }^{30}$ to achieve the desired thicknesses. The SU-8 patterns (Figure 1A) on $\mathrm{SiO}_{2}$ were fabricated employing the standard UV photolithography. The thus patterned structures were carbonized using a three-step pyrolysis process in an open ended quartz-tube furnace (RD Webb Red Mini \#40). First, the samples were heated under $\mathrm{N}_{2}$ (flow rate: $2000 \mathrm{sccm}$ ) at $300^{\circ} \mathrm{C}$ for 60 minutes. The temperature was ramped up at a rate of $10^{\circ} \mathrm{C} / \mathrm{min}$ to the final pyrolysis temperature $\left(800,900\right.$ and $\left.1000^{\circ} \mathrm{C}\right)$. The samples were kept at the final pyrolysis temperature for the desired dwell times (1, 4 and 8 hours for both 800 and $900^{\circ} \mathrm{C}$ ) before cooling down. One additional set of electrodes of the same dimensions were pyrolyzed at $1000^{\circ} \mathrm{C}$ with a dwell time of 1 hour. For prolonged dwell times, the samples used were $20 \mu \mathrm{m}$ thick before pyrolysis. For the $900^{\circ} \mathrm{C} / 1$ hour dwell time experiment, we worked with five electrodes of different thicknesses, 1, 5, 10, 20 and $30 \mu \mathrm{m}$ before pyrolysis. Before carrying out the electrochemical measurements, the electrodes were insulated with a Monokote tape in order to make sure that only a defined geometric area is exposed 




(A)

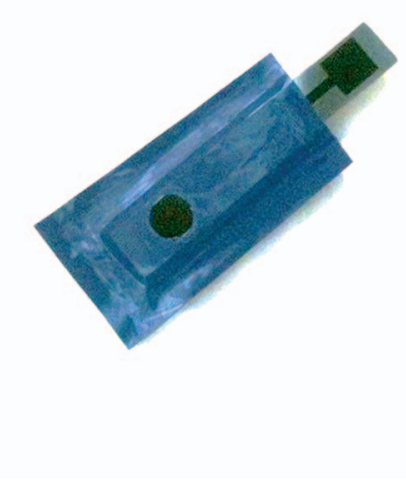

Figure 1. (a) Schematic diagram of the electrode design (b) photograph of an electrode on $\mathrm{SiO}_{2}$ after pyrolysis and insulation with Monokote tape.

$\left(0.07 \mathrm{~cm}^{2}\right)$ to the solution during the electrochemical experiments (Figure 1B).

Electrode characterization.- The thickness of the films before and after pyrolysis was measured on a profilometer (Veeco Dektak3). The resistivity of the electrodes was calculated using a two point probe resistance measurement unit (Keithly 2000 Sourcemeter) in a voltage range of -2.0 to $+2.0 \mathrm{~V}$. Raman spectroscopy was carried out on a Renishaw Raman Spectroscopy set up at $514.5 \mathrm{~nm}$. Spectra in the range of 1000 to $1800 \mathrm{~cm}^{-1}$ were obtained for the characterization of disordered (D) and graphitic (G) bands of carbon. X Ray Diffraction experiments were carried out on a Rigaku SmartLab X-ray Diffractometer.

All voltammetric measurements were carried out using a Palmsens electrochemical workstation at room temperature. A three electrode single compartment electrochemical cell was used for all our experiments with the fabricated carbon electrode as the working electrode, a platinum wire as the counter electrode and an $\mathrm{Ag} / \mathrm{AgCl}(\mathrm{KCl}$ saturated) reference electrode.

\section{Results and Discussion}

Effect of the substrate. - In order to study the electrochemical response of the electrodes pyrolyzed at different conditions and fabricated on different substrates, a series of cyclic voltammetry (CV) experiments was carried out using $\left[\mathrm{Fe}(\mathrm{CN})_{6}\right]^{4-}$ as a redox probe. This constitutes a reversible redox couple that exhibits an ideal CV behavior characterized by a difference between anodic and cathodic potential peaks $(\Delta \mathrm{E})$ of $59 \mathrm{mV} .{ }^{31}$ Another parameter that we took into account to evaluate the performance of the various electrodes is $I_{p}$. According to Randles Sevcik equation ${ }^{31} \mathrm{I}_{\mathrm{p}}$ is proportional to the electrode area, concentration and diffusion coefficient of the redox species and voltage scan rate. Since all these parameters are maintained constant in our experiments, a higher $\mathrm{I}_{\mathrm{p}}$ indicates a lower electrode resistance. Electrodes with a higher $I_{p}$ are considered more suitable in our experiments.

We UV photopatterned SU-8 on 4 different substrates namely bare silicon, silicon coated with silicon nitride, silicon coated with silicon oxide and sapphire. The native oxide film on the bare Silicon wafers was removed using a buffer HF etching solution. In order to test the effect of the substrate on the electrochemical behavior of the carbon electrodes on them we performed electrochemical experiments in solutions containing $1 \mathrm{mM}\left[\mathrm{Fe}(\mathrm{CN})_{6}\right]^{4-}$ and $0.1 \mathrm{M} \mathrm{KCl}$. The oxide and nitride layers offer the necessary insulation compared to bare silicon, which is a semiconductor. Silicon can act as a parallel resistance to the carbon electrodes, thereby drawing some amount of current in its path and increasing the overall resistance of the electrode. In this

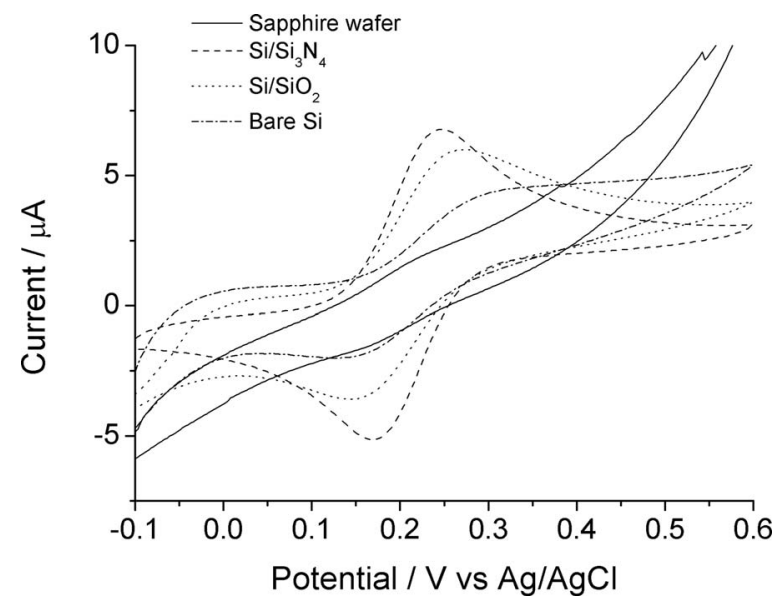

Figure 2. $\mathrm{CV}$ s recorded in $0.1 \mathrm{M} \mathrm{KCl}$ and $1 \mathrm{mM}\left[\mathrm{Fe}(\mathrm{CN})_{6}\right]^{4-}$ for pyrolyzed carbon electrodes fabricated on different substrates. Scan rate $25 \mathrm{mV} / \mathrm{s}$.

case, the electrode behaves as if the reaction was quasi-irreversible (high $\Delta \mathrm{E}$ ). Having an insulating oxide or nitride layer ensures that only carbon participates in the electron transfer between electrode and $\left[\mathrm{Fe}(\mathrm{CN})_{6}\right]^{4-} /\left[\mathrm{Fe}(\mathrm{CN})_{6}\right]^{3-}$ couple.

Out of the 4 substrates, silicon nitride gave the best results in terms of a narrow separation between anodic and cathodic peaks. This response however was only slightly better than that of $\mathrm{Si} / \mathrm{SiO}_{2}(10 \%$ higher $I_{p}$ and $15 \%$ lower $\Delta E$ ). For the rest of the experiments we chose oxide over nitride as we could thermally grow the oxide layer in our laboratory thus providing a cheaper alternative.

It is worth mentioning that carbon films on sapphire exhibited poor adhesion and often peeled off during pyrolysis. Hence we reduced the SU8 film thickness on sapphire to $2 \mu \mathrm{m}$ and the ramp rate to $5^{\circ} \mathrm{C} \mathrm{min}^{-1}$ which resulted in better adhesion. Thinner films increase the resistance of the electrode which is evident, for example, from the slope of the voltammograms in Figure 2 (the effect of thickness is also explained in section 3.3).

Effect of pyrolysis conditions on electrochemical behaviorElectrochemical and electrical characterization.- Pyrolysis of a polymer for converting it into carbon encompasses a mass loss due to the release of gases such as oxygen and hydrogen, leading to an isometric shrinkage of the structure. Thermogravimetric analysis (TGA) of pyrolyzed photoresist film reported by Ranganathn et al., ${ }^{32}$ suggests that $80 \%$ of the mass loss occurs at temperatures below $800^{\circ} \mathrm{C}$. Our results indicate a further $10 \%$ shrinkage in carbon films as the dwell time is increased from 1 hour to 4 hours at $800^{\circ} \mathrm{C}$ as well as at $900^{\circ} \mathrm{C}$.

The effect of increasing the final pyrolysis temperature on the electrochemical properties of the carbon films has been studied and reported previously. ${ }^{32,33}$ We demonstrate that a combined effect of temperature and dwell time leads to a much improved electrochemical performance of the SU-8 derived carbon. Figure 3A and 3B illustrates that both $\triangle \mathrm{E}$ and resistivity of our electrodes decrease on extending the dwell time from 1 to 8 hours. The curves represent $\Delta \mathrm{E}$ and resistivity values for electrodes pyrolyzed at 800 and $900^{\circ} \mathrm{C}$ with dwell times 1 , 4 and 8 hours. For a $1000^{\circ} \mathrm{C}$ pyrolysis temperature, we only carried out a one hour dwell since the $\Delta \mathrm{E}$ values were close to $59 \mathrm{mV}$ already.

Table I summarizes the $\Delta \mathrm{E}$ values, corrections for the uncompensated resistance (iR compensation) and calculations of the $\Delta \mathrm{E}$ values for electrodes pyrolyzed at different temperature and dwell times. The role of dwell time is quite evident in the improvement of the electrochemical response (narrower $\Delta \mathrm{E}$ and higher peak current). At $800^{\circ} \mathrm{C}$ there is approximately a $53 \%$ decrease in the $\Delta \mathrm{E}$ value as the dwell time is increased from 1 hour to 4 hour. Similarly, at $900^{\circ} \mathrm{C}, \Delta \mathrm{E}$ decreases by almost $38 \%$ as the dwell time is increased from 1 hour to 4 hour, reaching closer to the theoretical value of $59 \mathrm{mV}$. Moreover, a $34 \%$ reduction in $\Delta \mathrm{E}$ is observed when the temperature is increased 

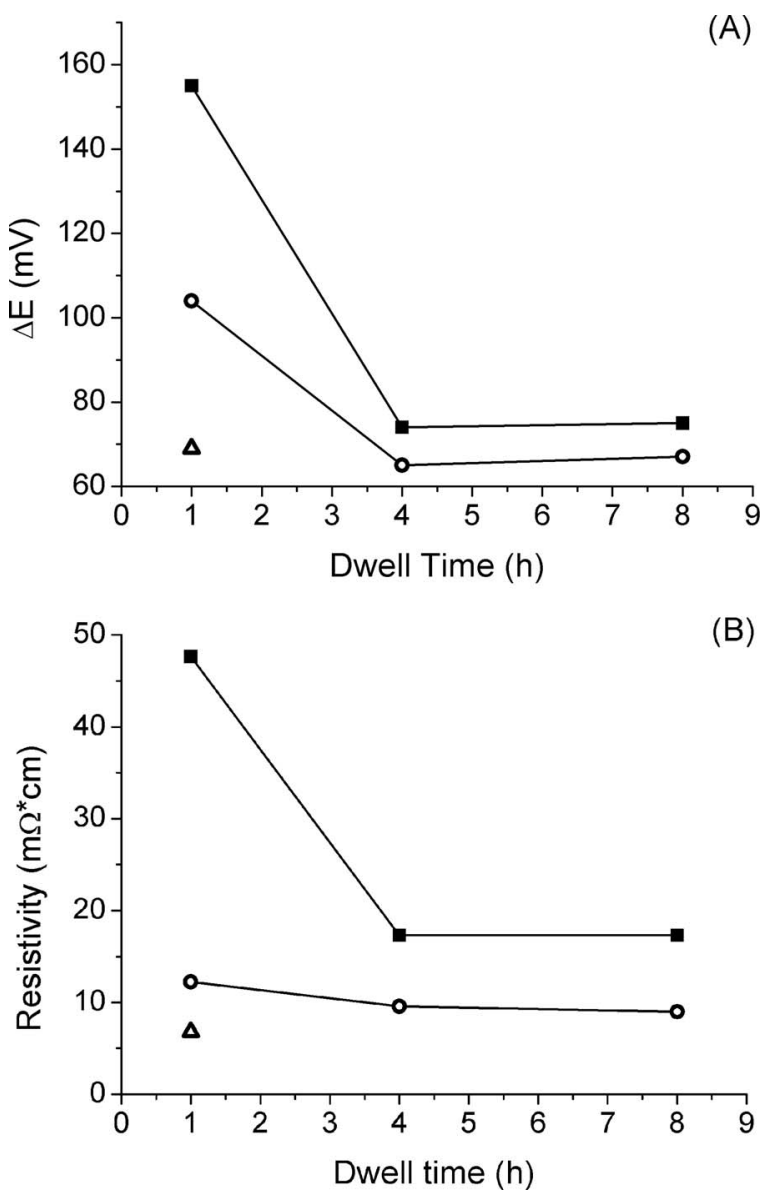

Figure 3. A: Effect of dwell time on the $\Delta \mathrm{E}$ for the oxidation of $\left[\mathrm{Fe}(\mathrm{CN})_{6}\right]^{4-}$ in $0.1 \mathrm{M} \mathrm{KCl}$ at $25 \mathrm{mV} / \mathrm{sec}$. Electrodes pyrolized at $800^{\circ} \mathrm{C}$ (squares), $900^{\circ} \mathrm{C}$ (circles) and $1000^{\circ} \mathrm{C}$ (triangle). B: Effect of the dwell time on the resistivity. Electrodes pyrolized at $800^{\circ} \mathrm{C}$ (squares), $900^{\circ} \mathrm{C}$ (circles) and $1000^{\circ} \mathrm{C}$ (triangle).

from $900^{\circ} \mathrm{C}$ to $1000^{\circ} \mathrm{C}$ for 1 hour dwell time. This behavior demonstrates that prolonged heat-treatment at specified temperature changes the properties of SU-8 derived carbon significantly.

We compared the behavior of electrodes at varying scan rates (5 to $50 \mathrm{mV} / \mathrm{seconds}$ ). In Table II are represented the $\Delta \mathrm{E}$ registered with two electrodes representing two limiting cases, namely $800^{\circ} \mathrm{C}$ pyrolyzed at 1 hour dwell, and $900^{\circ} \mathrm{C}$ pyrolyzed at 4 hour dwell. It is evident that the electrodes pyrolyzed at $800^{\circ} \mathrm{C}$ result in a narrower $\Delta \mathrm{E}$ while the carbon electrodes treated at $900^{\circ} \mathrm{C}$ for 4 hours do not. This behavior, which in principle also results from irreversibility of the redox reaction, is in this case principally attributed to high electrical resistance of the electrode material. The resistance measurements

Table I. Electrochemical and electrical data for electrodes pyrolyzed at different final temperatures and dwell times.

\begin{tabular}{ccccc}
$\begin{array}{c}\text { Temperature } \\
\text { and dwell time }\end{array}$ & $\begin{array}{c}\Delta \mathrm{E} \\
(\mathrm{mV})\end{array}$ & $\begin{array}{c}\text { Resistance } \\
(\Omega)\end{array}$ & $\begin{array}{c}\text { Corrected } \Delta \mathrm{E} \\
(\mathrm{mV})\end{array}$ & $\begin{array}{c}\text { Resistivity } \\
\left(\mathrm{m} \Omega^{*} \mathrm{~cm}\right)\end{array}$ \\
\hline $800^{\circ} \mathrm{C} 1 \mathrm{~h}$ & 155 & 1743 & 136 & 47.6 \\
$800^{\circ} \mathrm{C} 4 \mathrm{~h}$ & 74 & 701 & 64 & 17.3 \\
$800^{\circ} \mathrm{C} 8 \mathrm{~h}$ & 75 & 701 & 66 & 17.3 \\
$900^{\circ} \mathrm{C} 1 \mathrm{~h}$ & 104 & 459 & 98 & 12.2 \\
$900^{\circ} \mathrm{C} 4 \mathrm{~h}$ & 65 & 389 & 60 & 9.6 \\
$900^{\circ} \mathrm{C} 8 \mathrm{~h}$ & 67 & 365 & 63 & 9.0 \\
$1000^{\circ} \mathrm{C} 1 \mathrm{~h}$ & 69 & 283 & 63 & 6.8
\end{tabular}

*Resistance was measured between A and B in Fig. 1A

\begin{tabular}{|c|c|c|}
\hline $\begin{array}{l}\text { Scan Rate } \\
\left(\mathrm{mVs}^{-1}\right)\end{array}$ & $\begin{array}{c}\Delta \mathrm{E} \\
\left(800^{\circ} \mathrm{C} 1 \mathrm{~h} \text { dwell }\right)\end{array}$ & $\begin{array}{c}\Delta \mathrm{E} \\
\left(900^{\circ} \mathrm{C} 4 \mathrm{~h} \text { dwell }\right)\end{array}$ \\
\hline 5 & 97 & 69 \\
\hline 10 & 118 & 70 \\
\hline 25 & 161 & 74 \\
\hline 50 & 210 & 80 \\
\hline
\end{tabular}

confirmed that the resistance of the GC material in these two limiting cases described here are indeed significantly different (see below).

Spectroscopic characterization.--Raman spectra and XRD patterns for the carbon electrodes were obtained to investigate the graphitic nature of the carbon pyrolyzed under different conditions. The presence and area ratio of the characteristic " $D$ " $\left(1360 \mathrm{~cm}^{-1}\right)$ and "G" $\left(1582 \mathrm{~cm}^{-1}\right)$ bands in the Raman spectra have been studied extensively for determining the nature of the underlying carbon microstructures. ${ }^{34,35}$ A low value of the G/D ratio is an indicative of a smaller graphitic fraction, and is associated with the presence of a greater disorder. A typical spectrum is shown in Figure 4A.

We calculated the area ratio between $\mathrm{G} / \mathrm{D}$ (applying the corrections for overlapping peaks $)^{36}$ as function of pyrolysis time and temperature. Surprisingly we did not observe any significant increase in the graphitic content on dwell time extension. It is important to note that Raman spectroscopy for characterization of disordered and graphitic carbon is prone to errors as the peaks overlap partially.
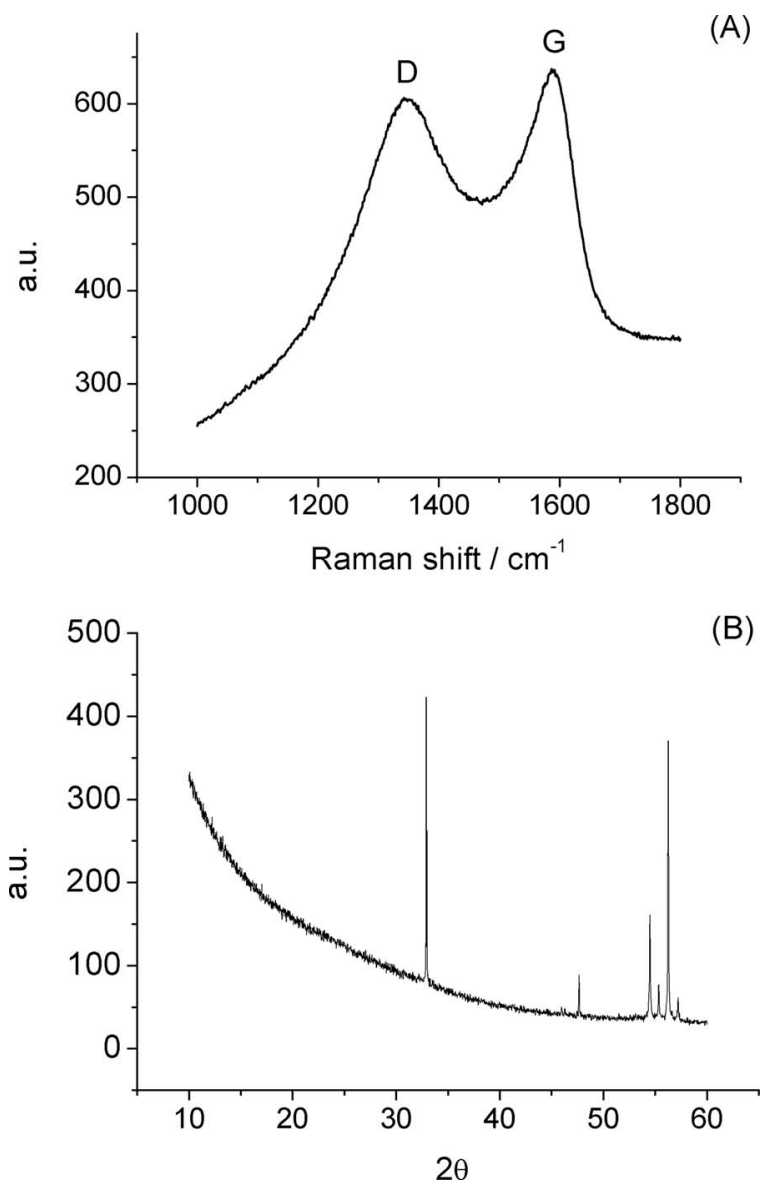

Figure 4. (A) Raman spectra and (B) X Ray Dyffraction patterns for SU8 derived carbon electrodes pyrolyzed at $900^{\circ} \mathrm{C}$ for $1 \mathrm{~h}$. 
Table III. Data taken from cyclic voltammograms at C-MEMS electrode, in solutions of $1 \mathrm{mM}\left[\mathrm{Fe}(\mathrm{CN})_{6}\right]^{4-}$ in 4 different concentrations of aqueous KCl.

\begin{tabular}{|c|c|c|c|c|c|c|c|c|}
\hline \multirow{2}{*}{$\begin{array}{l}\text { Scan rate } \\
\mathrm{mVs}^{-1}\end{array}$} & \multicolumn{2}{|c|}{$0.05 \mathrm{M} \mathrm{KCl}$} & \multicolumn{2}{|c|}{$0.1 \mathrm{M} \mathrm{KCl}$} & \multicolumn{2}{|c|}{$0.5 \mathrm{M} \mathrm{KCl}$} & \multicolumn{2}{|c|}{$1 \mathrm{M} \mathrm{KCl}$} \\
\hline & $\mathrm{E}_{1 / 2}(\mathrm{mV})$ & $\Delta \mathrm{E}(\mathrm{mV})$ & $\mathrm{E}_{1 / 2}(\mathrm{mV})$ & $\Delta \mathrm{E}(\mathrm{mV})$ & $\mathrm{E}_{1 / 2}(\mathrm{mV})$ & $\Delta \mathrm{E}(\mathrm{mV})$ & $\mathrm{E}_{1 / 2}(\mathrm{mV})$ & $\Delta \mathrm{E}(\mathrm{mV})$ \\
\hline 50 & 196 & 99 & 206 & 89 & 240 & 81 & 258 & 97 \\
\hline 25 & 197 & 90 & 208 & 81 & 241 & 75 & 259 & 87 \\
\hline 5 & 197 & 77 & 210 & 75 & 241 & 63 & 259 & 74 \\
\hline
\end{tabular}

The XRD spectra (Figure 4B) for all samples exhibit a peak at $\sim 54^{\circ}$, characteristic of the (004) planes of graphite. ${ }^{37}$ However, a bump extending from $10-25^{\circ}$ indicates the presence of greater amorphous regions. It is known that GC is composed of intertwined crystalline (graphite) ribbons, filled with amorphous carbons. ${ }^{38}$ These percolated graphite ribbons allow electron transport and make GC more suitable for electrical and electrochemical applications, unlike other amorphous materials. According to IUPAC ${ }^{39}$ if the crystalline structure of carbon can be detected in the material by diffraction methods, independent of the volume fraction and the homogeneity of distribution of such crystalline domains, the term 'graphitic' can be used. GC is therefore considered graphitic, which explains the presence of 004 planes at $54^{\circ}$ in our XRD spectra. The area of this peak however does not increase significantly for samples pyrolyzed at different dwell times. Figure 4B represents one characteristic spectrum. The additional peaks appearing at $33^{\circ}$ can be attributed to Silicon.

The change in electrical resistance and electrochemical behavior of electrodes pyrolyzed at different conditions is generally expected to result from enhanced graphitization. However in our experiments this enhancement seems to be small, which is not detectable by Raman spectroscopy and XRD. For small sample volume, such as a thin carbon films, electrical and electrochemical measurements prove to be more sensitive compared to spectroscopic techniques. Even minor changes in the underlying carbon microstructure can lead to a much different electrical behavior due to an improved electron transport. These microstructural changes can result from an overall increase in graphitization, or from a different orientation of graphitic planes in GC due to rearrangement of the carbon atoms during extended dwell, or both. We are currently carrying out a much detailed investigation in our group to address these questions.

Effect of film thickness on the resistance and on electrochemical behavior.- To determine the effect of film thickness and the change in electrical resistance that goes with that on $\Delta \mathrm{E}$, we fabricated SU8 electrodes of different thicknesses on $\mathrm{SiO}_{2}$ wafers. In Figure 5 the thicknesses of the electrodes after pyrolysis at $900^{\circ} \mathrm{C}$ for 1 hour and their respective resistance and $\Delta \mathrm{E}$ values are illustrated.

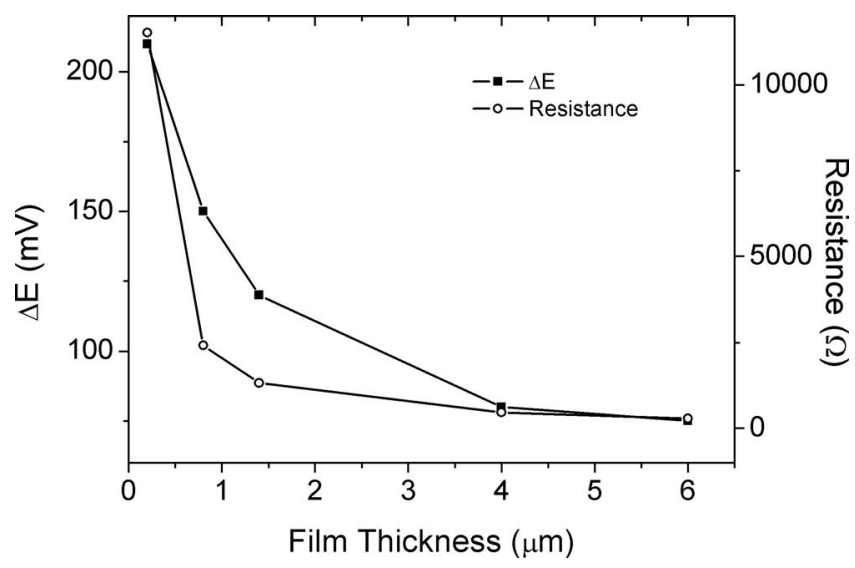

Figure 5. Difference in anodic and cathodic peak potential $(\Delta \mathrm{E})$ and resistance for different film thicknesses and keeping other dimensions constant.
In this case we decided to plot resistance (instead of resistivity) because the starting material and the pyrolysis parameters are the same. Since resistivity is a property of the material (instead of geometry) this parameter is not affected by thickness. The values we found were in fact all in good agreement one with the others.

As the thickness of the carbon film decreases, the end to end resistance (between point A and B in Figure 1A) goes up, which in turn increases the $\triangle \mathrm{E}$ and the electrodes are no longer ideal for electrochemical applications. We can conclude from this data (collected for $900^{\circ} \mathrm{C}, 1 \mathrm{~h}$ ) that there is a minimum required thickness ( $\sim 4 \mu \mathrm{m}$ for the given electrode dimensions, see also Figure 1) which gives a quasiideal response. Thicker films don't bring significant improvement of the electrochemical performances.

Effect of the supporting electrolyte concentration.- In order to explore the potential of these electrodes for a wide range of electrochemical applications, we studied the effect of the electrolyte concentration on the standard potential of ferro/ferrricyanide couple.

Figure 6 shows $\mathrm{CVs}$ for the $1 \mathrm{mM}\left[\mathrm{Fe}(\mathrm{CN})_{6}\right]^{4-}$ in solutions containing four different concentrations of $\mathrm{KCl}$ (from 0.05 to $1 \mathrm{M}$ ) at $5 \mathrm{mVs}^{-1}$. From Table III can be observed that $\mathrm{E}_{1 / 2}$ changes with the electrolyte concentration. Such behavior, which was demonstrated previously for Pt microelectrodes, ${ }^{40}$ can only arise if the formal potential for the ferro/ferrricyanide depends on the concentration of $\mathrm{KCl}$.

As per the Nernst equation (equation 1) to determine the equilibrium potential of a half cell in an electrochemical cell, the activity of the redox species is expressed as product of an activity coefficient $(\gamma)$ and the concentration $(\mathrm{C})$.

$$
\mathrm{E}=\mathrm{E}^{0}-(\mathrm{RT} / \mathrm{nF}) \ln \left(\gamma_{\mathrm{r}} / \gamma_{\mathrm{o}}\right)-(\mathrm{RT} / \mathrm{nF})\left(\mathrm{C}_{\mathrm{r}} / \mathrm{C}_{\mathrm{o}}\right)
$$

In the absence of supporting electrolyte $\gamma_{\mathrm{r}}=\gamma_{\mathrm{o}}$ but in the presence of added salt the activity coefficients for both oxidized and reduced species change, ${ }^{41}$ which in turn explains the shift.

This data demonstrates that the carbon derived from pyrolyzed photoresist can be used to study redox reaction kinetics as the electrochemical behavior of these electrodes is similar to that of the

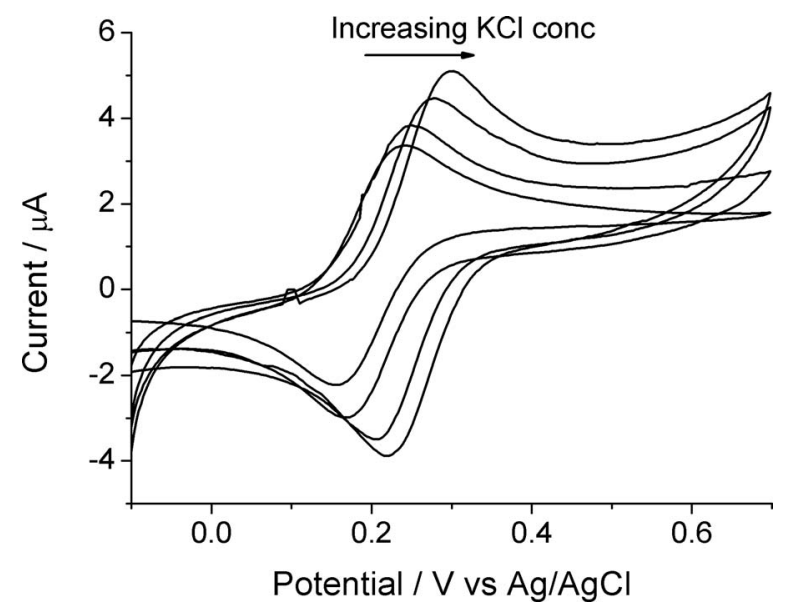

Figure 6. $\mathrm{CV}$ recorded using CMEMS electrode, at $5 \mathrm{mV} / \mathrm{s}$, in solution of $1 \mathrm{mM}\left[\mathrm{Fe}(\mathrm{CN})_{6}\right]^{4-}$ and four different concentrations of $\mathrm{KCl}$ (from 0.05 to $1 \mathrm{M})$. 

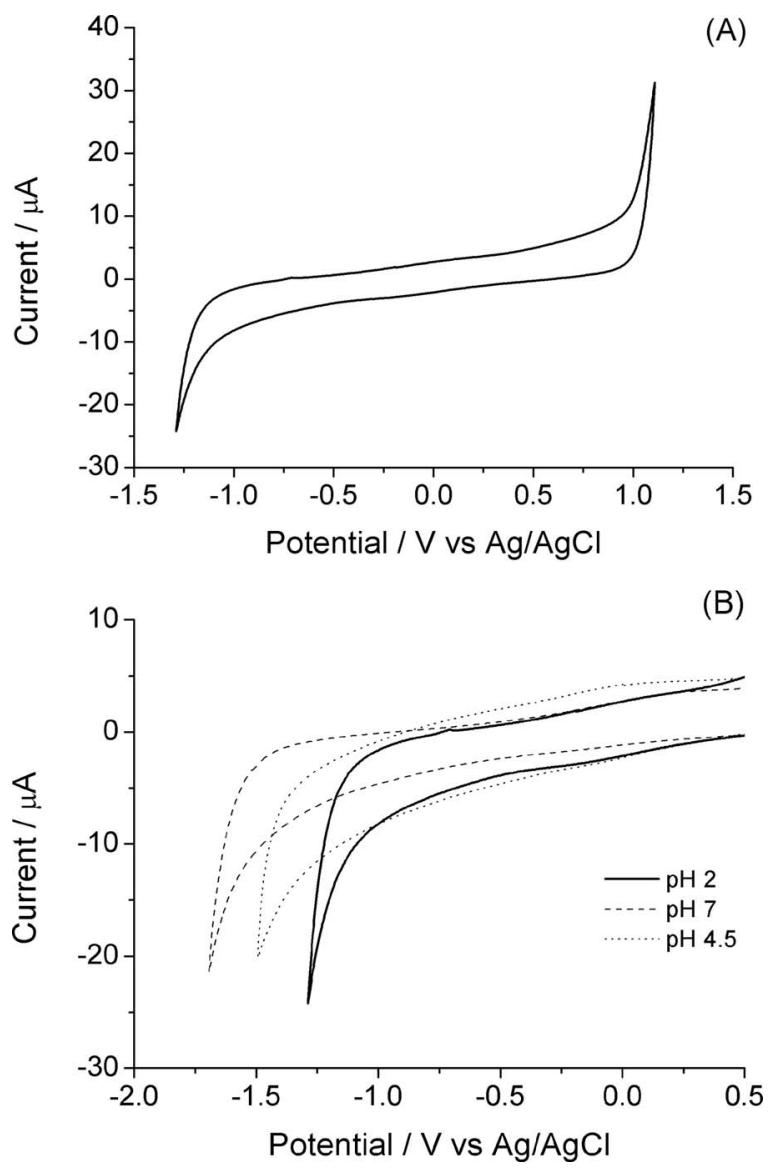

Figure 7. A) Background cyclic voltammogram recorded at $25 \mathrm{mV} \mathrm{s}^{-1}$ in $10^{-2} \mathrm{M} \mathrm{HCl}, \mathrm{pH} 2.2$. B) Background cyclic voltammograms recorded at $25 \mathrm{mV} \mathrm{s}^{-1}$ at a carbon electrode in: $10^{-2} \mathrm{M}$ phosphate buffer, $\mathrm{pH} 7.0$ (dashed line); $10^{-2} \mathrm{M}$ acetate buffer, $\mathrm{pH} 4.5$ (dotted line); (solid line).

traditionally used electrodes such as noble metals (Pt, $\mathrm{Au}$ ) or commercially available glassy carbon.

Accessible potential window. - It is also important to explore both the accessible potential window and the electrochemical behavior of the photoresist derived carbon electrodes at negative potential values. Figure 7A presents a CV recorded in $0.01 \mathrm{M} \mathrm{HCl}(\mathrm{pH} 2)$ in the absence of dissolved oxygen which shows that the potential window can go down to $1.4 \mathrm{~V}$ in acidic media.

Repetitive scanning to $-1.3 \mathrm{~V}$ at C-MEMS electrode in acidic media didn't give any change in the double layer charging currents demonstrating the stability of these electrodes also in extreme $\mathrm{pH}$ values.

As previously demonstrated in the literature, ${ }^{42}$ the nature of the increase in the background current in the cathodic range is made clear by examining its $\mathrm{pH}$ dependence. The voltammograms in Fig. 7B clearly show that these currents are attributable to proton reduction; indeed, the potential value at which a certain reduction current is measured shifts negatively by $60 \mathrm{mV}$ per unit increase in the $\mathrm{pH}$ of the solution.

Anodic stripping voltammetry of $C d(I I)$ and $P b(I I)$ at Bi modified carbon electrodes. - The electroanalytical performance of the previously described carbon electrodes was studied for the first time in the simultaneous determination of lead and cadmium through anodic stripping voltammetry (ASV). In situ surface modification of SU-8 derived carbon electrodes with bismuth was performed in order to increase the overpotential for hydrogen evolution in the cathodic range, thus, enabling detection of both analytes.
(A)

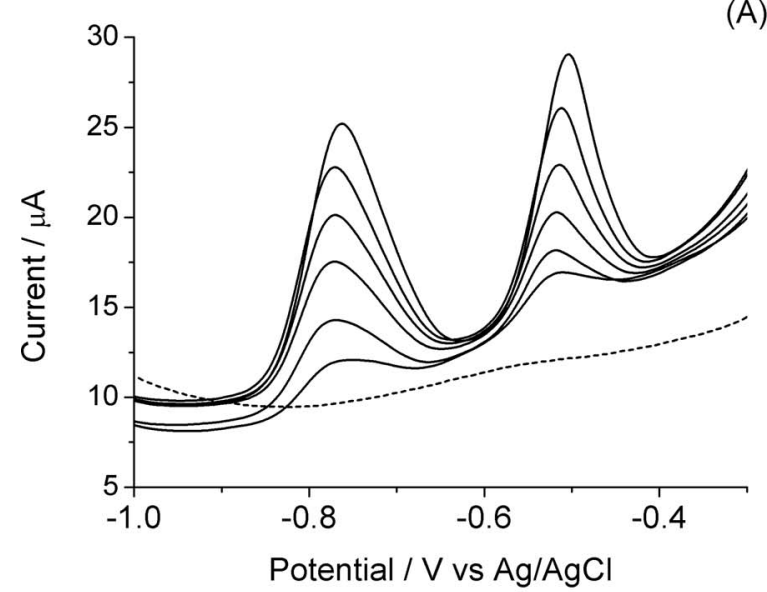

(B)

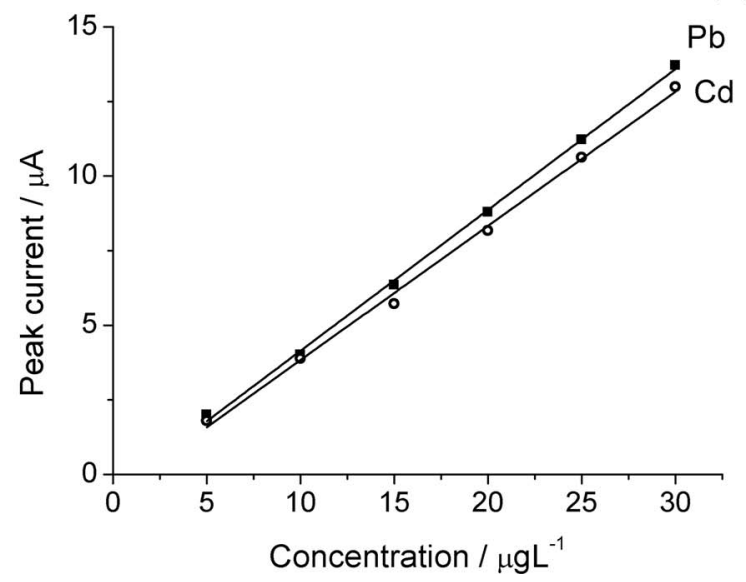

Figure 8. A) SW-ASV recorded at the in-situ prepared Bi-carbon electrode in $0.1 \mathrm{M}$ acetate buffer ( $\mathrm{pH} 4.5$ ), $10 \mathrm{mg} \mathrm{L}^{-1} \mathrm{Bi}(\mathrm{III})$ in the absence (dotted line) and presence of increasing concentrations of $\mathrm{Pb}(\mathrm{II})$ and $\mathrm{Cd}(\mathrm{II})$, from 5 to $30 \mu \mathrm{g} \mathrm{L}^{-1}$ (full lines). Deposition at $-1.1 \mathrm{~V}$ for $300 \mathrm{~s}$. SWV parameters: frequency $20 \mathrm{~Hz}$, amplitude $50 \mathrm{mV}$, potential step of $5 \mathrm{mV}$. B) Corresponding calibration plots.

Bismuth electrode exhibits a cathodic part of the operational potential window which is very similar to that of mercury, with even superior performance in the presence of dissolved oxygen. Due to its non-toxic character and excellent electroanalytical performance, bismuth electrodes have been exploited for various electroanalytical applications. ${ }^{43-45}$

In-situ modified carbon electrode was studied while increasing the concentration of $\mathrm{Pb}(\mathrm{II})$ and $\mathrm{Cd}(\mathrm{II})$ in the range of 5 and $30.0 \mu \mathrm{gL}^{-1}$, as shown in Figure 8A and 8B.

The electrode revealed a good linear behavior in the examined concentration range for both analytes in combination with $300 \mathrm{~s} \mathrm{ac}-$ cumulation time being the stripping signals well good separated and surrounded by low background contribution. The detection limit (DL) was calculated by using the $3 \sigma / \mathrm{m}$ criterion and resulted $0.8 \mu \mathrm{gL}^{-1}$ for $\mathrm{Pb}$ (II) and $0.7 \mu \mathrm{gL}^{-1}$ for $\mathrm{Cd}(\mathrm{II})$, which are close to those obtained with commercially available glassy carbon substrates. ${ }^{46,47}$

\section{Conclusions}

We carried out pyrolysis of SU-8 patterns at different temperatures and dwell times and demonstrated the effect of these conditions on the electrochemical behavior of the thus derived carbon. The electrodes are also characterized by Raman spectroscopy, XRD, and resistance measurements. Carbon electrodes pyrolyzed at $900^{\circ} \mathrm{C}$ for 4 hours display near-ideal electrochemical behavior. We also investigated the 
influence of substrate and electrode thickness on electrochemistry of carbon. We found that the electrodes fabricated on $\mathrm{Si}_{3} \mathrm{~N}_{4}$ and $\mathrm{SiO}_{2}$ substrates display better electrochemical response compared to those fabricated on bare silicon. We also tested electrode fabrication on to sapphire substrate, however a poor adhesion of carbon films on sapphire caused SU8 films thicker than 2 ìm to peel-off during pyrolysis. Pyrolyzed photoresist carbon electrodes have been applied for the first time as substrates for the simultaneous determination of $\mathrm{Cd}$ (II) and $\mathrm{Pb}$ (II) through anodic stripping voltammetry and DL as low as 0.7 and $0.8 \mu \mathrm{gL}^{-1}$ were calculated. Carbon constitutes excellent material for electrochemical applications that can be optimized employing the pyrolysis conditions we reported. C-MEMS process can lead to various two and three dimensional electrode designs suitable for a wide range of next generation electrochemical sensors.

\section{Acknowledgments}

This work was supported financially by MIUR-Rome (2010AXENJ8), Regione Veneto (RESMIA) and Biomems Group at UC Irvine. The authors acknowledge Talin Ayvazian (Department of Chemical Engineering and Materials Science, University of California, Irvine) for skillfull assistance in the Raman analysis.

\section{References}

1. K. Kinoshita, Carbon Electrochemical and Physico-chemical Properties, John Wiley \& Sons, New York (1988).

2. R. J. Taylor and A. A. Humffray, Electroanalytical Chemistry and lnterfacial Electrochemistry, 42, 347 (1973).

3. A. Adenier, M. M. Chehimi, I. Gallardo, J. Pinson, and N. Vila, Langmuir, 20, 8243 (2004).

4. P. Allongue, M. Delamar, B. Desbat, O. Fagebaume, R. Hitmi, J. Pinson, and J. M. Savéant, J. American Chem. Soc., 119, 201 (1997).

5. T. M. Florence, Journal of Electroanalytical Chemistry and Interfacial Electrochemistry, 27, 273 (1970).

6. Y. C. Sun, J. Mierzwa, and M. H. Yang, Talanta, 44, 1379 (1997).

7. I. Švancara, C. Prior, S. B. Hočevar, and J. Wang, Electroanalysis, 22, 1405 (2010).

8. S. B. Hocevar, I. Švancara, B. Ogorevc, and K. Vytřas, Analytical Chemistry, 79, 8639 (2007).

9. X. Dai, O. Nekrassova, M. E. Hyde, and R. G. Compton, Anal. Chem., 76, 5924 (2004).

10. X. Dai and R. G. Compton, Anal. Sci., 22, 567 (2006).

11. P. Ugo, L. M. Moretto, and G. A. Mazzocchin, Analytica Chimica Acta, 305, 74 (1995).

12. P. Ugo and L. M. Moretto, Electroanalysis, 7, 1105 (1995).

13. J. Wang, Electroanalysis, 17, 7 (2005).

14. C. Wang, L. Taherabadi, G. Jia, M. Madou, Y. Yeh, and B. Dunn, Electrochemical and Solid-State Letters, 7, A435 (2004).
15. C. Wang, G. Jia, L. Taherabadi, and M. Madou, Journal of Microelectromechanical Systems, 14, 348 (2005).

16. T. Maitra, S. Sharma, A. Srivastava, Y. K. Cho, M. Madou, and A. Sharma, Carbon, 50, 1753 (2012)

17. K. Pan, H. Ming, Y. Liu, and Z. Kang, New J. Chem., 36, 113 (2012).

18. J. Dong, W. Shen, and B. Tatarchuk, Appl. Phys. Lett., 80, 3733 (2002)

19. H. Shen, L. Zhang, M. Liu, and Z. Zhang, Theranostics, 2, 283 (2012).

20. Q. He, S. Wu, Z. Yin, and H. Zhang, Chem. Sci., 3, 1764 (2012).

21. K. Bosnick, N. Gabor, and P. L. McEuen, Appl. Phys. Lett., 89, 163121 (2006).

22. S. Ilani, L. A. K. Donev, M. Kindermann, and P. L. McEuen, Nat. Phys., 2, 687 (2006).

23. V. Sazonova, Y. Yaish, H. Ustunel, D. Roundy, T. A. Arias, and P. L. McEuen, Nature, 431, 284 (2004).

24. G. S. Bisht, S. Holmberg, L. Kulinsky, and M. J. Madou, Langmuir, 28, 14055 (2012).

25. S. Sharma, A. Sharma, Y.-K. Cho, and M. Madou, Applied Material and Interfaces, 4, 34 (2012).

26. G. T. Teixidor, R. Gorkin, P. P. Tripathi, G. S. Bisht, M. Kulkarni, T. K. Maiti, T. K. Battacharyya, J. R. Subramaniam, A. Sharma, B. Y. Park, and M Madou, Biomed. Mater, 3, 034116 (2008).

27. J. A. Lee, S. Hwang, J. Kwak, S. Park, S. S. Lee, and K. C. Lee, Sensors and Actuators $B, \mathbf{1 2 9}, 372(2008)$

28. M. K. Zachek, P. Takmakov, B. Moody, R. M. Wightman, and G. S. McCarty, Anal. Chem., 81, 6258 (2009).

29. C. Wang and M. J. Madou, Biosens. Bioelectron. 20, 2181 (2005).

30. http://microchem.com/pdf/SU82000DataSheet2025thru2075Ver4.pdf.

31. A. J. Bard and L. R Faulkner, Electrochemical Methods Fundamentals and Applications, second edition, Wiley, John Wiley \& Sons, New York (2001).

32. S. Ranganathan, R. McCreery, S. M. Majji, and M. Madou, Journal of the Electrochemical Society, 147, 277 (2000).

33. J. Kim, X. Song, K. Kinoshita, M. Madou, and R. White, Journal of the Electrochemical Society, 145, 2314 (1998).

34. R. L. McCreery, Chem Rev., 108, 2646 (2008).

35. Y. Wang, D. Alsmeyer, and R. L. McCreery, Chem. Mater, 2, 557 (1990).

36. L. Binsheng and L. Peichang, Journal of High Resolution Chromatography \& Chromatography Communications, 10, 449 (1987).

37. J. Zhao, L. Yang, F. Li, R. Yu, and C. Jin, Carbon, 47, 744 (2009).

38. G. M. Jenkins and K. Kawamura, Polymeric Carbons - Carbon Fibre, Glass and Char, Cambridge University Press, 1976.

39. IUPAC Compendium of Chemical Terminology (second edition 1997), 67, 493 (1995).

40. C. Beriet and D. Pletcher, J. of Electroanal. Chem., 361, 93 (1993).

41. J. Kielland, J. Am. Chem. Soc., 59, 1675 (1937).

42. B. Brunetti, P. Ugo, L. M. Moretto, and C. R. Martin, J. of Electroanal. Chem., 491, 166 (2000).

43. J. Wang, Electroanalysis, 17, 1341 (2005)

44. E. A. Hutton, B. Ogorevc, S. B. Hočevar, and M. R. Smyth, Analytica Chimica Acta, 557, 57 (2006).

45. A. Mardegan, S. Dal Borgo, P. Scopece, L. M. Moretto, S. B. Hočevar, and P. Ugo, Electrochemistry Communications, 24, 28 (2012).

46. A. Economou, Trends in Analytical Chemistry, 24, 334 (2005)

47. F. Arduini, J. Q. Calvo, A. Amine, G. Palleschi, and D. Moscone, Trends in Analytical Chemistry, 29, 1295 (2010). 